\title{
Transgender Women's Experiences with Stigma, Trauma, and Attempted Suicide in the Dominican Republic
}

Henna Budhwani ${ }^{1 *}$, Kristine R. Hearld ${ }^{1}$, Adrienne N. Milner ${ }^{2}$, Rebecca Charow ${ }^{3}$, Elaine McGlaughlin ${ }^{4}$, Rosa Mayra Rodriguez-Lauzurique ${ }^{5}$, Santo Rosario ${ }^{3}$ and Robert Paulino-

1: University of Alabama at Birmingham, 1665 University Boulevard, Birmingham, AL 35294

2: Queen Mary University of London, 58 Turner Street, London E1 2AB

3: Centro de Orientación e Investigación Integral (COIN), Calle Arzobispo Meriño, Santo Domingo, Dominican Republic

4: Caribbean Vulnerable Communities Coalition (CVC), Kingston, Jamaica

5: Institute for Tropical Medicine \& Global Health, Universidad Iberoamericana, Santo Domingo, República Dominicana

Corresponding: Henna Budhwani, PhD, MPH

University of Alabama at Birmingham

Health Care Organization and Policy

517D Ryals Public Health Building

1665 University Boulevard

Birmingham, AL 35294

Phone: (205) 975-7613

Fax: (205) 975-7685

budhwani@uab.edu

Keywords:

Transgender Women; Dominican Republic; Attempted Suicide; Stigma; Violence; Assault 


\section{ABSTRACT}

Background: Studies on attempted suicide in transgender populations, particularly those in resource-limited settings are scarce. We examined the relationships between stigma, trauma, and suicide attempts in a national sample of transgender women from the Dominican Republic. Methods: Bivariate analysis examined differences between suicide attempters and nonattempters $(n=298)$. Multivariate analysis reported odds ratios with attempted suicide as the outcome $(n=260)$. Results: About a quarter of respondents $(23.9 \%)$ experienced sexual abuse, $12.3 \%$ were tortured and $20.3 \%$ experienced a murder attempt. More than a quarter reported using illegal drugs. Independent sample t-tests found significant differences between suicide attempters and non-attempters. Attempters were more likely to have experienced sexual abuse, psychological abuse, torture, and a murder attempt $(p<.001$ for all). Respondents who experienced psychological abuse had over three times higher odds of attempting suicide, compared to respondents who had not $(\mathrm{OR}=3.203, \mathrm{p}<.01)$. Experience with torture and attempted murder were associated with higher odds of attempting suicide $(O R=2.967, p<.05$ and $\mathrm{OR}=2.894, \mathrm{p}<.05$ respectively). Conclusions: Although some nations have implemented anti-discrimination policies protecting transgender citizens, these policies are often not consistently enforced. Eliminating stigmatizing policies may reduce rates of negative health outcomes subsequently improving population health. 


\section{BACKGROUND}

Transgender women are routinely marginalized, stigmatized, and victimized; this is particularly true in the Dominican Republic where non-traditional gender identities are viewed with contempt thereby perpetuating and reinforcing institutional discrimination. (CONAVIHSIDA, 2012; PAHO, 2014) Specifically, $30 \%$ of transgender women in the Dominican Republic reported encountering discrimination in the workplace, $45 \%$ encountered discrimination in educational settings, and one-third believed it was too difficult to access health care services out of fear of rejection, shame, and embarrassment. (CONAVIHSIDA, 2012; Hasbún, 2012) These experiences with trauma, stigma, and discrimination are hallmark risk factors for suicide and attempting suicide (Clements-Nolle et al., 2006; Nock et al., 2008), and reduce the likelihood that transgender women in the Dominican Republic will seek care for their mental illnesses and suicidal ideation. (PAHO, 2014) Although, we know that gender and sexual minorities are at greater risk for attempting suicide as compared to their cisgender peers, few suicide studies are available on transgender populations, and we known even less about the suicide behavior of transgender women in resource-limited settings. (WHO, 2014) The majority of suicide research has been conducted in high-income, industrialized nations. (Dyregrov, 2011; WHO, 2014) Considering this knowledge gap, we examined associations between experiences with stigma, discrimination, trauma, and attempted suicide in a national sample of transgender women residing in the Dominican Republic.

Globally, over 800,000 people die from suicide annually, and $75 \%$ of these deaths occur in low- and middle-income countries (LMIC). (WHO, 2014) Structural barriers to accessing mental health care are more common in LMICs where health surveillance systems, mental health resources, and services for prevention, identification, treatment and support are limited. (WHO, 2014) In the Dominican Republic, almost half of suicides (48.1\%) occur in citizens aged 20 to 44 years, (ONE, 2014) and suicides are concentrated in the Dominican Republic's largest urban and most populated cities: Santo Domingo and Santiago. (ONE, 2014) Specific to 
transgender populations, prevalence of suicide attempts range widely from $16 \%$ in Washington D.C. to as high as $50 \%$ in Chile. (Moody and Smith, 2013; PAHO, 2014) In the latter Chilean study, $87.5 \%$ of respondents reported being depressed; this rate was markedly higher than that of the non-transgender matched peer-group where $5 \%$ reported that they attempted suicide and 20\% reported depression. (PAHO, 2014) In another matched peer-group study from Sweden, transgender respondents were five times more likely to attempt suicide and nineteen times more likely to commit suicide when compared to the matched cisgender peer-group. (Dhejne et al., 2011)

General risk factors for suicide, suicidal ideation, and suicide attempts include depression, childhood abuse, experience with trauma, substance abuse, and other mental health conditions (Meyer, 2003). Suicide attempts in gender and sexual minorities are influenced by an additional set of more specific risk factors including: experience with stigma, discrimination, victimization, social exclusion, low socioeconomic status, low educational attainment, and homelessness. (Clements-Nolle et al., 2006; Goldblum et al., 2012; Haas et al., 2014; Meyer, 2003; Nock et al., 2008; Kim et al., 2016). Exposure to both sets of risk factors, regardless of gender or minority status, is associated with elevated levels of stress, mental illness, suicide, suicidal ideation, and attempted suicide. (Clements-Nolle et al., 2006; Goldblum et al., 2012; Haas et al., 2014; Meyer, 2003; Nock et al., 2008; House et al., 2011, Hatzenbuehler et al., 2014) Gender-based violence also increases likelihood of attempted suicide by four-fold in transgender people and the more often a transgender person experiences violence, the greater the number of lifetime suicide attempts she will make. (Goldblum et al., 2012) Moreover, transgender persons who are rejected by family and friends, especially transgender women who have experienced verbal and physical abuse, are more socially vulnerable, more likely to use drugs as a coping mechanism, and more likely to develop poor mental health outcomes. (Haas et al., 2014, Kaplan et al., 2016, Grossman and D’Augelli, 2007) 
Traumatized and stigmatized individuals often use drugs, both illicit and prescription, as a coping mechanism. (Choi et al., 2016; Rahim et al., 2015) The United Nations Office on Drugs and Crime (UNODC) estimated that worldwide, 250 million people used at least one illicit drug in 2014. Of these, more than $12 \%$, or over 29 million people total, were considered problem drug users, or suffering from a drug use disorder or dependence (UNODC, 2016). Historically, Caribbean studies have almost exclusively focused on drug transportation and seldom acknowledged drug-related health and social welfare consequences; however, a recent study out of the Dominican Republic suggested that drug access was heavily situated in high tourism areas, particularly where sex workers, transgender women, and tourists congregated, thereby ostensibly increasing transgender women's exposure to drugs. (Guilamo-Ramos et al., 2015)

The root cause of the many trauma-related risk behaviors (e.g. suicide) and coping mechanisms (e.g. drug use) is stigma. Stigma is the process by which a group of individuals, such as transgender women, is labeled socially undesirable or deviant and is therefore devalued due to their attributes or behaviors that are societally perceived to be "deeply discrediting". (Goffman, 1963; Turan et al., 2016) Because stigma is a fundamentally social process requiring an "us," versus "them," stigma is perpetuated and reinforced by social structure and interpersonal interactions. (Link and Phelan, 2006; Turan et al., 2016) There are three domains of stigma: perceived stigma, enacted stigma, and internalized stigma. (Berger et al., 2001; Phillips et al., 2011) Studies among sexual minorities suggest that exposure to any of these three types of stigma is associated with higher rates of suicide and attempted suicide. (Cho and Sohn, 2016; Hatzenbuehler et al., 2014; Perez-Brumer et al., 2015) Since stigma marginalizes an individual or a population, those belonging to a stigmatized group cease to be regarded as "normal," (Goffman, 1963) effectively exposing them to social rejection because of belonging to the stigmatized group. (Goffman, 1963) Thus, this stigma can discourage transgender women from seeking mental health treatment or contribute to noncompliance with their treatment regimens. (Link \& Phelan Link and Phelan, 2006) 
In an analysis of the General Social Survey/National Death Index data, results showed shorter life expectancy by approximately twelve years in sexual minorities living in high-stigma communities compared with those living in more inclusive areas; causes of this life expectancy gaps where suicide, homicide, and cardiovascular disease. (Hatzenbuehler et al., 2014)

Additionally, increased odds of suicide attempts in transgender adults were strongly associated with internalized stigma, specifically transphobia. (Perez-Brumer et al., 2015) Considering the empirical evidence on suicide in transgender populations, as well as the implications of stigma theory, we hypothesize that transgender women in the Dominican Republic will 1) Exhibit high rates of depression, 2) Have experienced multiple forms of stigma and trauma, and that 3) Stigma and trauma, along with depression will be associated with attempted suicide in our sample.

\section{METHODS}

Data from the 2015 Dominican Republic Transgender Health Needs Study (THNS) were analyzed $(n=299)$. These data were collected by Centro de Orientación e Investigación Integral (COIN), and the study was funded by the National Council for HIV and AIDS (CONAVIHSIDA). Quantitative data were collected through facilitated interviews with transgender women participants. The questionnaire collected data on: a) Demographics b) Sex Partners c) Sexual history d) Use of condoms and lubricants e) Sexually Transmitted Infections f) Health Care g) Gender Violence h) Stigma and discrimination i) Use of hormones and other feminization processes j) Inclusion and social exclusion, and k) Stress experienced by minorities. This study leveraged the PLACE method of data collection recommended by the Joint United Nations Programme on HIVIAIDS (UNAIDS).

El Consejo Nacional de Bioética en Salud, (CONABIOS) in the Dominican Republic provided ethical approval for the implementation of this study. Informed consent was collected verbally. Verbal consent is a modality often used in participatory action research when working 
with low literacy populations. (Marshall, 2007; Tindana et al., 2006) We have found verbal consent, when designed and implemented thoughtfully, leads to thorough comprehension of the study and of voluntary participation as opposed to securing written consent, which may cause psychosocial discomfort when the respondent cannot read or write. (Krogstad et al., 2010; Tekola et al., 2009) The University of Alabama at Birmingham's Institutional Review Board provided ethical approval for secondary data analysis (\#N150803004).

\section{Dependent Variable}

Attempting suicide was a dichotomous variable representing whether or not respondents answered affirmatively to the question "Have you attempted suicide?" (1=yes; 0=no).

\section{Independent Variables}

Age, income, and educational attainment were included as demographic controls. Age was continuous in years. Monthly income in pesos was measured categorically $(1=0-1000 ; 2=1001$ 5000; 3=5001-10000; 4=more than 10001 pesos). Educational attainment was measured using dummy variables (primary school or less, secondary school, or post-secondary school (technical school or university), with primary school or less serving as the reference category.

We included trauma due to stigma, depression, and drug use in our analysis. Trauma was represented by four separate dichotomous measures of whether the respondent since turning 14 years old had experienced 1) sexual abuse, 2) psychological abuse, 3) torture, and 4) if someone had attempted to kill the respondent (yes=1; $0=n o)$. These terms were presented simply without additional definitions; thus, the respondent reported on her understanding of these terms (e.g. torture). Depression was assessed by asking respondents to describe how to best describe her daily life situation in the last 6 months in terms of whether they "felt depressed." Responses were coded into three dummy variables (never depressed, sometimes depressed, or always depressed) with never feeling depressed in her daily life situation serving 
as the reference category. Illicit drug use was measured with a dichotomous variable which asked the respondent about her illicit drug use in the past 6 months ( $1=y e s, 0=$ no).

\section{Statistical Analyses}

In addition to completing univariate and bivariate analyses $(n=298)$, we employed multivariate analysis using logistic regression with attempted suicide as our outcome. Listwise deletion resulted in $n=260$. All analyses were conducted in IBM SPSS Statistics 24.

\section{RESULTS}

\section{Descriptive Statistics}

Descriptive statistics, both univariate and bivariate, are reported in Table 1 . The average age of our sample was 26.0 years with those who attempted suicide being slightly younger (25.0) than those who had not (26.2). Approximately a quarter of respondents had a monthly income of over 10,000 pesos per month and roughly $21 \%$ of the sample had a primary school education or less. Between one fifth and one quarter of respondents had attempted suicide $(22.5 \%)$.

We found a high level of trauma present in our sample. Almost half $(46.0 \%)$ of respondents experienced some form of trauma; $23.9 \%$ experience sexual abuse, $33.0 \%$ experienced psychological abuse, $12.3 \%$ were tortured, and $20.3 \%$ experienced a murder attempt on her life. The rate of trauma (any of the four types) was over $80 \%$ in those who had attempted suicide as compared to about a third (36.3\%) in those who had not attempted suicide. Rates of depression were also high; $73.6 \%$ of the sample reported feeling sometimes or always depressed in the last 6 months. More than a quarter of the sample $(26.1 \%)$ reported using illegal drugs in the past 6 months.

A directionally consistent pattern emerged in our univariate and bivariate results.

Transgender women who attempted suicide experienced higher rates of trauma than those who did not. Independent sample t-tests showed significant differences between suicide attempters 
and non-attempters. Attempters more likely to have experienced sexual abuse, psychological abuse, torture, and a murder attempt ( $p<.001$ for all types of trauma). Suicide attempters were also more likely to have been depressed $(p<.001)$, to have used illicit drugs in the last 6 months $(p<.05)$, had lower levels of monthly income $(p<.05)$, and had a primary school level education or less $(p<.01)$ than non-attempters.

[Table 1 about Here]

\section{Multivariate Analyses}

Table 2 presents results for the multivariate analysis employing logistic regression.

Psychological abuse, torture, and experiencing a murder attempt were significantly associated with the likelihood of reporting a suicide attempt. Respondents who experienced psychological abuse had over three times higher odds of attempting suicide compared to respondents who had not experienced psychological abuse $(\mathrm{OR}=3.203, \mathrm{p}<.01, \mathrm{Cl}=1.456,7.048)$. Similarly, experiencing torture and a murder attempt were associated with nearly three times higher odds of attempting suicide compared to those who had not been tortured $(\mathrm{OR}=2.967, \mathrm{p}<.05$, $\mathrm{Cl}=1.456,7.048)$ or who had not experienced a murder attempt $(\mathrm{OR}=2.894, \mathrm{p}<.05, \mathrm{Cl}=1.238$, 6.764). Respondents who experienced sexual abuse did not have higher odds of attempting suicide relative to respondents who had not experienced sexual abuse.

Depression was also significantly associated to attempting suicide. Compared to transgender women who never felt depressed, respondents who sometimes felt depressed had over four times higher odds of attempting suicide ( $O R=4.026, p<.05, C l=1.232,13.154)$. Respondents who used illicit drugs had over two times higher odds of attempting suicide $(\mathrm{OR}=2.292, \mathrm{p}<.05, \mathrm{Cl}=1.020,5.150)$. Low monthly income, age, and low educational attainment were not significantly associated with attempted suicide. 
[Table 2 about Here]

\section{DISCUSSION}

We proposed three hypotheses on the rates and relationships of included variables; we found statistical support for all three hypotheses. Our key findings were that 1) the rate of attempted murder on the lives of transgender women in our sample was high, and 2) Experiencing a murder attempt was statistically associated with attempting suicide. Although studies exist on the effects of stigma, victimization, and trauma, rarely are the effects of attempted murder on suicide or suicide attempts statistically assessed. Having said this, the interpersonal theory of suicide (Joiner, 2005) provides a framework to contextualize our results. This theory asserts that certain individuals are at greater risk to attempt or commit suicide due to three key components: thwarted belongingness, perceived burdensomeness, and acquired capability (Baumeister and Leary, 1995; Hoyer and Lund, 1993; Joiner et. al, 2007). Belongingness is considered a social need for mental well-being; in a society wherein transgender populations are stigmatized they may experienced thwarted belongingness or a lack of belonging, and this lack has been associated with greater risk to attempt suicide. (Baumeister and Leary, 1995; Hoyer and Lund, 1993; Joiner et. al, 2007) Additionally, the high rates of experienced trauma, such as murder attempts, could increase our participants' acquired capability for attempting suicide. The less an individual fears death, which is a result of exposure to pain and suffering that is proximal to death, the more likely she is to attempt suicide; basically suicide and suicide attempts are related to being desensitized to dying. If a transgender woman in the Dominican Republic experiences a murder attempt on her life, the interpersonal theory of suicide (Joiner, 2005) suggests she could become more likely to attempt suicide, which aligns with our results.

Limitations should be carefully considered when applying findings. First, bias is expected in self-reported, survey data, especially when the population is stigmatized, such as transgender women. Some of our measures lacked specificity, reducing extensibility of our findings. As 
mentioned previously, certain terms, such as torture, were not defined; thus, respondents were left to interpret the meaning of these words. Moreover, we are unaware as to if transgender women who responded having attempted suicide did so before or after experiencing trauma. We are also unable to ascertain if respondents who experienced victimization contacted the police or local authorities seeking prosecution. Our sample size was small; more comprehensive data collection could provide deeper insight. Finally, causality cannot be inferred from crosssectional data. Future studies should consider our limitations when designing and implementing subsequent studies with this same population.

\section{Policy Implications}

In the Dominican Republic, although Article 42, the right to integrity, and Article 39, the right to equality, stipulate that all men and women have the right to live without violence and cannot be discriminated against based on gender and other personal and social conditions, Article 330 of the Criminal Code is often used by police officers to justify harassment, which stipulates that fines or up to 2 years of imprisonment can be imposed when same-sex couples engage in public displays of affection as a violation of decorum and good behavior in public. (D.R. Const., 2015) There are no explicit discrimination protection laws and so, technically it is not illegal to discriminate on account of sexual orientation or gender identity. Due to the amended wording of Article 55, rights of the family, marriage, civil unions or domestic partnerships are only recognized between a man and women. Although not explicitly discriminatory against transgender persons, these policies increase the vulnerability of transgender women and men who live in or visit the Dominican Republic. In contrast, there are protective laws; however, these laws are not uniformly or consistently enforced (PAHO, 2014). For instance, Law 285-66, Article 210 that prohibits sodomy between officers of the same-sex, commonly is not enforced, (D.R. Const., 2015) especially in the cases where officers have coerced sexual favours from transgender sex workers. (Hasbún, 2012) So, although the Dominican Republic has protective 
laws, is a member state of the Organization of American States (OAS), and is part of numerous United Nations System and Inter-American System for the Protection of Human Rights treaties and declarations, human rights violations and violence are not condemned and do not routinely achieve justice. (PAHO, 2014) Therefore, the vulnerabilities experienced by transgender persons, especially transgender persons in the Dominican Republic, could be eased by understanding of impact of policies that promote or allow harm to transgender citizens, retiring discriminatory policies, and implementing and enforcing protective policies designed to ensure human rights are not violated. (Winter et al., 2016b)

\section{Conclusion}

Globally, transgender women are traumatized, stigmatized, and stripped of their human rights. Although progress has been made to support transgender rights in some high-income nations, this advancement has not occurred universally in resource-poor settings. (Winter et al., 2016b) The transgender community continues to be traumatized at high rates, which robs transgender persons of respect and dignity and has detrimental effects on physical health, mental health, and social wellbeing. (Budhwani et al., 2016; Reisner et al., 2016; Winter et al., 2016a, 2016b; Wylie et al., 2016) 


\section{REFERENCES}

Berger, B.E., Ferrans, C.E., Lashley, F.R., 2001. Measuring stigma in people with HIV: psychometric assessment of the HIV stigma scale. Res. Nurs. Health. 24(6), 518-529.

Baumeister, R.F. and Leary, M.R. 1995. The need to belong: Desire for interpersonal attachments as a fundamental human motivation. Psychological Bulletin. 117, 497-529

Budhwani, H., Turan, B., Hasbun, J., Rosario, S., Tillotson, L., McGlaughlin, E., Waters, J., 2016. Association between violence exposure and condom non-use among transgender sex workers in the Dominican Republic: the mediating role of trust, Int J STD AIDS. pii: 0956462416659421. (Epub ahead of print).

Centers for Disease Control and Prevention (CDC), 2016. Suicide: Consequences. http://www.cdc.gov/violenceprevention/suicide/consequences.html (accessed 16.10.25)

Cho, B., Sohn, A., 2016. How do sexual identity, and coming out affect stress, depression, and suicidal ideation and attempts among men who have sex with men in South Korea? Osong Public Health Res. Perspect. 7(5), 281-288.

Choi, N.G., DiNitto, D.M., Marti, C.N., Choi, B.Y., 2016. Association of adverse childhood experiences with lifetime mental and substance use disorders among men and women aged 50+ years. Int Psychogeriatr. 1-14. (Epub ahead of print).

Clements-Nolle, K., Marx, R., Katz, M., 2006. Attempted suicide among transgender persons: The influence of gender-based discrimination and victimization. J. Homosex. 51(3), 53-69.

Consejo Nacional para el VIH y sida (CONAVIHSIDA), 2012. Segunda Encuesta de Vigilancia de Comportamiento con Vinculación Serológica en Poblaciones Claves: Gais, Trans y Hombres que tienen sexo con Hombres (GTH), Trabajadoras Sexuales (TRSX), Usuarios de Drogas (UD). Diseño Grafico, Santo Domingo. Spanish.

Dhejne, C., Lichtenstein, P., Boman, M., Johansson, A.L., Långström, N., Landén, M., 2011. Long-term Follow-up of Transsexual Persons Undergoing Sex Reassignment Surgery: Cohort Study in Sweden. PLoS One. 6(2), e16885.

Dominican Republic Constitution, 2015.

https://www.constituteproject.org/constitution/Dominican_Republic_2015.pdf (accessed 16.10.25)

Dyregrov, K., 2011. What do we know about needs for help after suicide in different parts of the world? A phenomenological perspective. Crisis. 32(6), 310-318.Goffman, E., 1963. Stigma; notes on the management of spoiled identity. Prentice-Hall, Englewood Cliffs.

Goldblum, P., Testa, R. J., Hendricks, M. L., Bradford, J., \& Bongar, B., 2012. The relationship between gender-based victimization and suicide attempts in transgender people. Professional Psychology: Research and Practice. 43, 468-475. 
Grossman, A.H., D’Augelli, A.R., 2007. Transgender youth and life-threatening behaviors. Suicide Life Threat. Behav. 37(5), 527-537.

Guilamo-Ramos, V., Lee, J.J., Ruiz, Y., Hagan, H., Delva, M., Quiñones, Z., Kamler, A., Robles, G., 2015. Illicit drug use and HIV risk in the Dominican Republic: tourism áreas créate drug use opportunities. Glob Public Health. 10(3), 318-330.

Haas, A. P., Rodgers, P. L., Herman, J. L., 2014. Suicide attempts among transgender and gender non-conforming adults: UCLA: The Williams Institute and American Foundation for Suicide Prevention. http://williamsinstitute.law.ucla.edu/wp-content/uploads/AFSP-WilliamsSuicide-Report-Final.pdf (accessed 16.10.25)

Hasbún, J., 2012. Focus Right-Diversity and Commonality- a look at Female and Transgender sex workers in three Caribbean Countries. The Caribbean Vulnerable Communities Coalition (CVC), El Centro de Orientación e Investigación Integral (COIN), Pan Caribbean Partnership Against HIV and AIDS (PANCAP), CARICOM Community Secretariat, Santo Domingo.

Hatzenbuehler, M.L., Bellatorre, A., Lee, Y., Finch, B.K., Muennig, P., Fiscella, K., 2014. Structural stigma and all-cause mortality in sexual minority populations. Soc. Sci. Med. 103, 3341.

Herek, G., Gillis, J. R., Cogan, J. C., 2009. Internalized stigma among sexual minority adults: Insights from a social psychological perspective. Journal of Counseling Psychology. 56, 32-43.

House, A.S., Van Horn, E., Coppeans, C., Stepleman, L.M., 2011. Interpersonal trauma and discriminatory events as predictors of suicidal and nonsuicidal self-injury in gay, lesbian, bisexual, and transgender persons. Traumatology. 17(2),75.

Hoyer, G. and Lund, E. 1993. Suicide among women related to number of children in marriage. Archives of General Psychiatry. 50, 134-137

Joiner, T.E. 2005. Why People Die By Suicide. Cambridge, MA: Harvard University Press.

Joiner, T.E., Hollar, D., and Van Orden, K.A. 2007. On Buckeyes, Gators, Super Bowl Sunday, and the Miracle on Ice: 'Pulling together' is associated with lower suicide rates. Journal of Social and Clinical Psychology. 25, 180-196

Kaplan, R.L., Nehme, S., Aunon, F., de Vries, D., Wagner, G., 2016. Suicide risk factors among trans feminine individuals in Lebanon. Int. J. Transgend. 17(1), 23-30.

Kim, J.L., Kim, J.M., Choi, Y., Lee, T.H., Park, E.C., 2016. Effect of Socioeconomic Status on the Linkage Between Suicidal Ideation and Suicide Attempts. Suicide Life Threat. Behav. 46(5), 588-597.

Krogstad, D,J., Diop, S., Diallo, A., Mzayek, F., Keating, J., Koita, O.A., Touré, Y.T., 2010. Informed Consent in International Research: The Rationale for Different Approaches. Am J Trop Med Hyg. 83(4), 743-747.Link, B.G., Phelan, J.C., 2006. Stigma and its public health implications. Lancet. 367(9509), 528-529. 
Marshall, P.A., 2007. Ethical challenges in study design and informed consent for health research in resource-poor settings. Special Topics in Social, Economic and Behavioural (SEB) Research report series, No. 5. World Health Organization, Geneva.

Meyer, I.H., 2003. Prejudice, social stress, and mental health in lesbian, gay, and bisexual populations: conceptual issues and research evidence. Psychol Bull. 129(5), 674-697.

Moody, C., Smith, N.G., 2013. Suicide Protective Factors Among Trans Adults. Arch. Sex Behav. 42(5), 739-752.

Nock, M.K., Borges, G., Bromet, E.J., Cha, C.B., Kessler, R.C., Lee, S., 2008. Suicide and Suicidal Behavior. Epidemiol Rev. 30, 133-154.

Oficina Nacional de Estadistica (ONE), 2014. Anuario de estadísticas-muertes accidentals y violentas 2014. http://www.one.gob.do/Categoria/Publicaciones/1457 (accessed 16.10.27)

Pan American Health Organization (PAHO), John Snow, Inc., World Professional Association for Transgender Health, et al., 2014. Blueprint for the Provision of Comprehensive Care for Trans Persons and Their Communities in the Caribbean and Other Anglophone Countries. John Snow, Inc., Arlington.

Perez-Brumer, A., Hatzenbuehler, M.L., Oldenburg, C.E., Bockting, W., 2015. Individual- and Structural-Level Risk Factors for Suicide Attempts among Transgender Adults. Behav. Med. 41(3), 164-171.

Phillips, K.D., Moneyham, L., Tavakoli, A., 2011. Development of an instrument to measure internalized stigma in those with HIVIAIDS. Issues Ment. Health Nurs. 32(6), 359-366.

Rahim, M., Patton, R., 2015. The association between shame and substance use in young people: a systematic review. PeerJ. 3, e737.

Reisner, S., Poteat, T., Keatley, J., Cabral, M., Mothopeng, T., Dunham., E, Holland, C.E., Max, R., Baral, S.D., 2016. Global health burden and needs of transgender populations: a review. Lancent. 388(10042), 412-436.

Tekola, F., Bull, S.J., Farsides, B., Newport, M.J., Adeyemo, A., Rotimi, C.N., Davey, G., 2009. Tailoring Consent to Context: Designing an Appropriate Consent Process for Biomedical Study in a Low Income Setting. PLoS Negl Trop Dis. 3(7), e482.

Tindana, P.O., Kass, N., Akweongo, P., 2006. The Informed Consent Process in a Rural African Setting: A Case Study of the Kassena-Nankana District of Northern Ghana. IRB. 28(3), 1-6.

Turan, B., Budhwani, H., Browning, W.R., Goodin, B., Raper, J.L., Mugavero, M.J., Turan, J.M., 2016. How does stigma affect people living with HIV? The mediating roles of internalized and anticipated HIV stigma in the effects of perceived community stigma on health and psychosocial outcomes. AIDS Behav. 21(1), 283-291.

United Nations Office on Drugs and Crime, 2015. World Drug Report 2015.United Nations Sales No. E.15.XI.6., Vienna. 
United Nations Office on Drugs and Crime, 2016. World Drug Report 2016.United Nations Sales No. E.15.XI.7., Vienna.

Winter, S., Diamond, M., Green, J., Karasic, D., Reed, T., Whittle, S., Wylie, K., 2016.

Transgender people: health at the margins of society. Lancet. 388(10042), 390-400.

Winter, S., Settle, E., Reisner, S., Cabral, M., Knudson, G., Baral, S., 2016. Synergies in health and human rights: a call to action to improve transgender health. Lancet. 388(10042), 318-321.

World Health Organization (WHO), 2014. Preventing suicide: A global imperative. Geneva, Switzerland.

Wylie, K., Knudson, G., Khan, S.I., Bonierbale, M., Watanyusakual, S., Baral, S., 2016. Serving transgender people: clinical care considerations and service delivery models in transgender health. Lancet. 388(10042), 401-411. 


\section{TABLES}

Table 1. Descriptive Statistics for Study Variables

\begin{tabular}{lcccc}
\hline Variable & $\begin{array}{c}\text { \% Of } \\
\text { Sample } \\
(n=298)\end{array}$ & $\begin{array}{c}\% \text { Of } \\
\text { Attempters } \\
(n=67)\end{array}$ & $\begin{array}{c}\text { \% Of Non- } \\
\text { Attempters } \\
(n=231)\end{array}$ & $t(d f)$ \\
\hline Attempted Suicide & 22.5 & 100.0 & 00.0 & \\
Experienced Trauma & 46.0 & 80.7 & 36.3 & $7.386(115.525)^{\star * *}$ \\
$\quad$ Sexual Abuse & 23.9 & 47.7 & 17.1 & $4.548(85.536)^{\star * *}$ \\
$\quad$ Psychological Abuse & 33.0 & 63.1 & 24.5 & $5.790(94.360)^{* * *}$ \\
$\quad 12.3$ & 35.9 & 5.7 & $4.847(71.348)^{\star * *}$ \\
$\quad$ Torture & 20.3 & 50.8 & 11.6 & $5.938(79.518)^{\star * *}$ \\
$\quad$ Attempted Murder & 26.4 & 7.5 & 31.9 & $-5.461(194.251)^{\star * *}$ \\
Depression (Never Depressed) & 26.1 & 39.3 & 22.6 & $2.433(84.856)^{*}$ \\
Drugs (Used Illicit Drugs) & 25.3 & 15.6 & 28.1 & $-2.265(123.549)^{*}$ \\
Income (>10,001 pesos/month) & 21.1 & 36.4 & 16.7 & $3.050(88.513)^{\star *}$ \\
Education (Primary or Less) & 26.0 & 25.0 & 26.2 & $-1.171(116.259)$ \\
Mean Age & & & \\
\hline
\end{tabular}

$\overline{* \star *} p<.001^{* *} p<.01^{*} p<.05$ 
Table 2. Odds Ratios for Logistic Regression of Attempted Suicide ( $n=260)$

\begin{tabular}{lcc}
\hline Variables & OR & $95 \% \mathrm{Cl}$ \\
\hline $\begin{array}{l}\text { Experienced Trauma } \\
\quad \text { Sexual Abuse }\end{array}$ & 1.702 & $0.736,3.936$ \\
$\quad$ Psychological Abuse & $3.203^{* *}$ & $1.456,7.048$ \\
$\quad$ Torture & $2.967^{*}$ & $1.063,8.280$ \\
$\quad$ Attempted Murder & $2.894^{*}$ & $1.238,6.764$ \\
Depressed & & \\
$\quad$ Always & 2.054 & $.354,11.938$ \\
$\quad$ Sometimes & $4.026^{*}$ & $1.232,13.154$ \\
Illicit Drug Use & $2.292^{*}$ & $1.020,5.150$ \\
Monthly Income & 0.702 & $0.470,1.049$ \\
Education & & \\
$\quad$ Secondary School & 0.524 & $0.219,1.250$ \\
$\quad$ Post Secondary School & 0.623 & $0.199,1.947$ \\
Age & 0.963 & $0.911,1.019$ \\
Pseudo $R$ Squared & 0.249 & \\
\hline$* *$ P & & \\
\hline
\end{tabular}

${ }^{* *} p<.001^{* *} p<.01{ }^{*} p<.05$ 